\title{
A New Approach to Managing Community Participation and Stakeholder Negotiation in South African Local Government
}

\section{Enslin J van Rooyen}

\section{School of Public Management and Administration, University of Pretoria}

\section{ABSTRACT}

Community participation currently forms an important element of the South African government's policy on integrated development planning in local government. Community participation and stakeholder negotiation involve a process of comprehensive engagement, as divergent opinions, needs and expectations normally exist. It is therefore important to correctly identify legitimate stakeholders, to know the different types of partnerships that form stakeholder units within municipalities, and where final decision-making responsibility and accountability are located in local government affairs. This paper reflects on the need for a culture of community participation and most importantly, stakeholder negotiation to be established and institutionalized to the extent that it will be viewed not as an event but rather a continuous process in local government. This approach defines a new era for public management in South African local government.

JEL D73, H70

\section{INTRODUCTION}

Traditionally, South Africa does not have a culture of actively engaging communities in local government development affairs. Democracy brought new emphasis to transparency in government activities, greater public accountability and the notion of respect for human rights. This approach significantly differs from the old-style paternalistic approach to managing development where community information and consultation was limited. Integrated municipal development planning, local economic development-projects, various forms of municipal partnerships, municipal taxation and services rating issues all require effective community participation processes. At this point in South Africa's development, such a culture therefore, needs to be actively inculcated. 
The question may be posed as to why stakeholder negotiation is emphasized where generally reference is only made to community participation. Normally, the concept community participation is employed to reflect the interactive processes of informing and consultation with communities. However, on the way to achieving true community participation in the management of local government affairs, processes of stakeholder negotiation, rather than mere information and consultation, are involved as well. Often, some form of negotiation needs to be entered into between different stakeholders to formulate appropriate policies and settle differences.

Following is a reflection on community participation and stakeholder negotiation and the role thereof in achieving particular desired outcomes for South African local government in the future. This paper calls for the entrenchment of a culture of community participation and most importantly, that stakeholder negotiation should be institutionalized to the extent that it will be viewed not as an event but rather a continuous process in local government. As municipal managers are consequently required to participate in such negotiations, they should ensure that they are well skilled in this regard. This approach defines a new dimension for public management in South African local government.

\section{STAKEHOLDER NEGOTIATION AS PART OF COMMUNITY PARTICIPATION}

While municipal integrated development planning-processes are unfolding and local economic development-projects are being launched, local communities should be afforded the opportunity to participate in processes to articulate their expectations and to prioritize their needs. This would in effect necessitate a process of comprehensive engagement with local stakeholders and where divergent opinions, needs and expectations exist, some form of negotiation should be entered into. It is not implied that in absolutely all cases actual negotiations, as one would expect in a bargaining forum-context, would be undertaken. This may become cumbersome and render municipalities ineffective. What, however, is necessary, is a process where communities are informed and made aware of - and even educated (Van der Walt \& Knipe, 1998: 143 and Coetzee, Graaf, Hendricks \& Wood (eds.), 2001: 473) - on the basics of what developmental local government could afford them; that they are stakeholders in municipal affairs in one way or the other; and the fact that in reality resource constraints are prevailing and therefore in most cases, projects and resources allocation are approved on the basis of priority. 
Interaction with stakeholders is currently an activity that is regarded as imperative for the successful planning, management and evaluation of development projects in the South African private and public sectors. In most university classes that examine entities' relationship with society, stakeholders and stakeholder management are among the first concepts introduced. Stakeholders are typically defined as " individuals and groups that have an involvement or an investment in the company's decisions and in its social and economic exchanges." (Beckenstein, Long, Arnold \& Gladwin, 1996: 2). Mersham, Rensburg and Skinner (1995: 57) concur with this view and emphasize that in terms of public relations and development communication in South Africa, communities and stakeholders are regarded as key communicators in communication and should therefore be actively be involved in the process. Communities and stakeholders should not merely be the passive recipients of information: interactivity and proper dialogue is required.

In a public management context, Fox and Meyer (1995: 122) define a stakeholder as "a person or group of people, such as shareholders, employees, customers, creditors, suppliers, trade unions, government and the community, who have an interest in the operation and outcomes of the organization." Van der Walt and Knipe (1998: 143) quote Paul (1987: 2) in defining community participation as "an active process in which the clients, or those who will benefit, influence the direction and implementation of a development project aimed at improving the welfare of people in terms of income, personal growth, independence and other values regarded as valuable". It can therefore be deduced that stakeholders may be regarded as those individuals or groupings whose existence may somehow be impacted upon by decisions and actions taken by particular organizations or institutions and who, in turn, may through their actions impact on the functioning of such organizations or institutions or the achievement of their goals. The above definitions clearly establish that stakeholders are those important roleplayers who participate in community affairs to achieve particular objectives. In a local government context, these objectives may be to formulate a budget or achieve certain developmental ideals, such as the establishment of a training facility.

In the South African Municipal Systems Act (Act 32 of 2000), the term stakeholder is not employed to refer to the above individuals or groupings. The Act merely mentions the word community, and refers to community participation to encapsulate the spirit of involving individuals and groupings within a community in the activities of local government and governance. However, it should be noted that merely practicing superficial community participation might not be sufficient to attain the objectives of developmental local government, especially from a sustainability point of view. Beckenstein, Long, Arnold and Gladwin (1996: 3) argue that mere community participation/ 
consultation - also referred to as regulatory processes - in developmental projects may form but an element of a bureaucratic structure that is often viewed, negatively, as impeding decision-making. It may well be that this is part of a "going through the motions"-process to legitimize the actions of any particular entity which does not embrace the true spirit of partnership and cooperation. In other words, it is a de facto retaining of the paternalistic approach towards development. In this regard the Batho Pele-principles, as contained in the White Paper on Transforming Public Service Delivery (1997), eight service delivery principles apply: Consultation, access, information, redress, service standards, courtesy, openness and transparency and value for money. However, to ensure that these principles are adhered to, communities should be awarded the opportunity to express their opinion in this regard, which in turn, necessitates intensive and thorough community participation in government affairs (Du Toit, Knipe, Van Niekerk, Van der Walt \& Doyle, 2001: 108).

Van der Walt and Knipe (1999: 144) view community participation as a very involved process and specifically mention the problem-solving mature thereof. However, Van der Walt and Knipe (1999: 144) note that practically community participation may present some daunting problems, inter alia: (a) the processes associated with managing projects where certain community members and groups may frustrate progress; (b) pressure on personnel as the process of participation and consultation requires additional human resources capacity; and (c) the unpredictability associated with dealing with community groups.

Tsenoli in Reddy (ed.) (1995: 34) sounds a warning that democratic local government and sustainable development could only be realized if facilities, resources and technical skills are provided to ensure that all development is truly people driven. Swanepoel and De Beer (1996: 16) confirm that development "is about people participating in decision-making and implementation that will affect their position and their future". The community as stakeholders in democratic local government should therefore actively become involved in all planning, implementation and monitoring processes. Such processes should also be supported by sufficient administrative capacity to ensure effectiveness.

According to Beckenstein et al. (1996: 3) the stakeholder concept is critical to sustainable development. It is emphasized that dialogue and negotiation among stakeholders are the vehicles through which the principles for sustainable behaviour are established, implemented and monitored. This form of community consultation is far removed from the more traditional regulatory processes that claim to include community participation when government institutions merely invite comment from stakeholders. Typically the inputs are then reviewed and incorporated into a programme that balances legislative intent with the concerns of the stakeholders (Beckenstein et al., 1996: 3). 
Concerning the concept of negotiation, Spoelstra and Pienaar (1996: 3) define it as "a process of interaction between parties directed towards reaching some form of agreement that will hold and which is based upon common interests, with the purpose of resolving conflict, despite widely dividing differences". Swanepoel and De Beer (1996: 16) mention that there are essentially three possible causes of conflict whilst managing community development projects: (a) clashing interests: (b) clashing personalities; and (c) misunderstanding. Each of these should be managed through a process of negotiation and by focussing on the causes of the conflict. Spoelstra and Pienaar (1996: 12) continue to classify the types of negotiation, two of which are important for local government stakeholder negotiations: Firstly, co-operative negotiation. In this type of negotiation win or lose is irrelevant. Conflicting views are discussed and converted into co-operation. Secondly, continuous negotiation, involves entering into an on-going relationship between the parties. This relationship is maintained throughout the negotiations and into the future.

Spoelstra and Pienaar (1996: 3) emphasize the nature of negotiations as being that of a process and not an event. An element of continuity therefore forms its basis. In addition, it is also important in this regard to note that negotiation involves an element of information exchange. From the point of view of local government, information dissemination could have the advantage that it assists in attaining the objective of transparency and greater accountability and that it may result in educating some communities in aspects related to their environment.

\section{POLICY ON STAKEHOLDER NEGOTIATIONS AND THE ROLE OF MANAGEMENT}

In policy-making stakeholder definition may become quite complex. As a process of stakeholder consultation is entered into, it is necessary to identify the affected parties (stakeholders) and to determine legitimate representation of these parties on the relevant structures. The Constitution of the Republic of South Africa (Act 108 of 1996) places an emphasis on the aspect of involving communities in decision-making (e.g. section 152) as well as on the need for sound intergovernmental relations and co-operative governance in local government. However, community involvement and representation on relevant structures should be balanced by the need to manage the process effectively (Beckenstein et al., 1996: 2). In local government one of the current debates center on the integrated development planning process and the associated stakeholder consultation process that should form an integral part of the structuring of the plans. The Municipal Systems Act (Act 32 of 2000) dedicates Chapter 4 to community participation in local government. It states that local 
government should develop a culture of community participation and municipal governance that complements formal representative government and should encourage and create conditions for local communities to participate in the affairs of the municipality in inter alia: (a) the preparation and implementation and review of its integrated development plan; (b) the establishment, implementation and review of its performance management system; (c) the preparation of its budget; and (d) strategic decisions relating to the provision of municipal services. The Municipal Systems Act (Act 32 of 2000) specifies that in each municipality mechanisms, procedures and processes for community participation should be put in place. Stipulations pertain to persons who are unable to submit their comments concerning any local government-related issue because of their disability or disadvantaged disposition or if they are unable to write are made in the Act. It is also stated (in section 22) that the Minister responsible for local government may regulate or issue guidelines pertaining to community participation in municipal affairs. So far, the Minister, however, had not regulated on this matter.

Municipal Managers, specifically, are required in terms of the Integrated Development Planning Guidelines issued by the Department of Provincial and Local Government, to be instrumental in structuring different community participation forums to facilitate a process of consultation for integrated development planning. The question arises as to how to proceed in entering into effective stakeholder consultation and consequently negotiations in local government. As has been stated before, there are some concerns related to the aspect of setting a policy for effective stakeholder negotiations: first, defining a stakeholder in a particular municipality; second, ascertaining the legitimacy of the representation of stakeholders on forums to conduct consultations and negotiations; and third, how much negotiations and consultation is sufficient to ensure a just reflection of community needs in planning and implementation management, without frustrating administrative processes.

Concerning the first two issues, Coetzee, Graaf, Hendricks and Wood (eds.) (2001: 478) mention that in constituting forums where negotiations are entered into with stakeholders, the following could serve as guidelines:

- Establish who are the significant decision-makers and influential people in a particular area.

- $\quad$ Ascertain whose interests these influential decision-makers serve.

- $\quad$ Find out how those members of the community generally excluded from the decision-making process hold these decision-makers in check and exert their own influence on the political process.

- $\quad$ Establish to what extent do present structures affect local participation in decision-making. 
Concerning the third issue, it should be noted that not all aspects of the day-today management of a project could be subjected to a comprehensive consultation process before decisions are taken. Van der Walt and Knipe (1988: 137) indicate a number of important responsibilities of public managers i.e. financial, political, legal and ethical. Although local governments need to regularly enter into consultation with their communities, municipal managers and the community each do play roles that are complementary but not identical. The essential difference is found in the responsibility and accountability aspects associated with the tasks of a Municipal Manager as the chief executive officer of a municipality. Steering committees and forums, on which representatives of communities serve, should not substitute the accountability (Van der Walt \& Knipe, 1998: 134) that should be borne by the local authority and specifically the Municipal Manager as the accountable officer.

In the guidelines set by the national Department of Provincial and Local Government pertaining to the Integrated Development Planning process, some policy principles on community participation are presented. The IDP Guide Pack (Guide 1: 39) refers to the emphasis placed on public participation by the White Paper on Local Government (1998). According to the IDP Guide Pack the primary objective of community participation is the promotion of local democracy. Local government is not only expected to find its own way in structuring stakeholder participation (IDP Guide Pack - Guide 1: 39) (because of the fact that national or provincial policy cannot prescribe detail requirements for local particularities) but it is expected to actively encourage and promote participation, especially in the case of marginalised groups and women (White Paper on Local Government, 1998, sec. 3.3) and (Municipal Systems Act, 2000, sec. 17).

The White Paper on Local Government (1998) proposes active community participation in local government by defining the four levels through which citizens and community groups may participate and influence municipal functioning.

On the first level voters have the opportunity to participate in a democratic process to elect candidates to represent them in local government affairs. Voters should be ensured of the maximum democratic accountability of the elected political leadership for the policies they are empowered to promote. Secondly, citizens should have the opportunity to express, through different stakeholder associations and groupings, their views before, during and after policy formulation processes to ensure that those policies address community needs as accurately as possible. On the third level consumers and end-users should be the recipients of value for money services and courteous and responsive service. On the fourth level, community members may participate in local government 
affairs as organized partners involved in the mobilization of resources for development via businesses, non-governmental organizations and communitybased organizations (Infra).

To achieve some of the above-mentioned ideals of community participation, both the IDP Guide Pack and the White Paper on Local Government (1998) require extended community participation processes and structures in municipalities by proposing the following:

1. The establishment of forums of organized formations (especially in the fields of visioning and on issue-specific policies).

2. Structured stakeholder participation in council committees (especially ad hoc issue-related committees).

3. Participatory action research, with specific focus groups (for in-depth information on specific issues).

4. Forming associations (especially for people in marginalised areas).

The above exposition indicates that participation should be a continuous and structured process and it should focus on certain specific processes with particular outcomes in mind. The decisions on how to structure and manage the particular mechanisms, processes and procedures to attain effective public participation are left to the individual municipalities. This allows for relevance and appropriateness to accommodate local peculiarities and avoids imposing isomorphic models of stakeholder participation.

However, the IDP Guide Pack (Guide 1: 40) to an extent, seems to question the wisdom of leaving the decision on ways and means of public participation to each municipality. The fear seems to exist that some municipalities may not be able to effectively engage in a process of community participation. In some cases, the previous Integrated Development Planning processes undertaken by South African municipalities did not adhere to the basic requirements to ensure effective community participation, as set in the Municipal Systems Act (Act 32 of 2000) and the White Paper on Local Government (1998). Some reasons forwarded as to why a more pronounced policy leadership is required to ensure stakeholder participation in the Integrated Development Planning process are as follows:

Completely different styles of democracy with highly diverging combinations of formal representative and participatory governance are established. In different municipalities different structures and systems, as allowed by legislation, are in operation. Community participation and stakeholder negotiations necessarily differ in form and intensity between well-resourced metropolitan municipalities with a large contingent of sophisticated stakeholders and poor rural 
municipalities that may consist of a largely unemployed and illiterate stakeholder contingent. In some cases residents were denied the right to actively participate in local government affairs since no minimum requirements were set in this regard. Lacking policy directives on community participation relating to establishing structures and setting procedures create helplessness and confusion on the side of most municipalities since they find it difficult to determine appropriate procedures of their own.

The Policy Paper on Integrated Development Planning (October 2000: 30) concurs that various South African municipalities have experienced problems related to the above in the past, but cautions that policy documents prescribing detailed ways in which stakeholder participation should be managed, will not address these problems. Municipalities should rather ensure compliance with the general requirements set for community participation in the Municipal Systems Act (Act 32 of 2000) but should "apply their own minds in developing contextually appropriate, and perhaps unique, ways of involving all segments of the municipality, and in building partnerships." As general guide towards effective participation, municipalities should take the following into account (Policy Paper on Integrated Development Planning, 2000: 30):

1. Mass meetings are not the most effective way to acquire information from the community.

2. Many different creative techniques exist (e.g. focus groups) that may be useful in attaining effective community participation.

3. Information technology may be of use to interact with communities and stakeholders. It should be borne in mind though, that access to these technologies is limited in some communities.

4. Participation should be carefully structured, as it may become time consuming and costly. This may particularly be the case in newly demarcated areas that are of large physical size and/or have a large and highly differentiated population.

Each municipality should find ways to establish a practical working relationship with all stakeholders. Such practical working relationships should adhere to the following principles: (a) it should move beyond mere "demands" associated with protest politics and which incorporates a more involved and participatory role; (b) it should take into account the particularities of local politics in South Africa - especially in the rural areas; and (c) it should recognize that communities often reflect division and competing interests and not often harmony and common purpose (Coetzee, Graaf, Hendricks \& Wood (eds.) 2001: 478).

In addition to the above, Coetzee, Graaf, Hendricks and Wood (eds.) (2001: 479) mention that power stuctures and relationships is becoming increasingly 
important in municipalities. Achieving true community participation is difficult. Local stakeholders tend to monopolize power and are often hostile toward comprehensive participation. It is therefore necessary that a negotiated working relationship should be established between all stakeholders in local government. Local government managers should accept that stakeholder negotiation is an ambiguous process where no one party is in charge. Individual stakeholders should be willing to note each other's interests and accept that traditional decision-making practice should be changed to accommodate these interests. Managers should be willing to support initiatives that may pose uncertain outcomes although they may find it safer and easier to operate within a regulated environment where the way forward is set.

Stakeholder negotiation in local government is not only reserved for local community members or community based organizations. Stakeholder negotiation may occur between other stakeholders as well: between business and local government, between the local and the district municipalities or between different spheres of government (e.g. district municipalities and provincial authorities). Other forms of stakeholder negotiations are to be found on an intrainstitutional level where different local government departments in the same council may find themselves competing and therefore eventually negotiating for the same resources. Only in this way will true municipal partnerships develop and could the principle of co-operative governance (on an inter- and an intrainstitutional context) really emanate.

\section{Municipal-community partnerships}

As community participation processes become increasingly institutionalized, practical municipal-community partnership ventures will become more prevalent. However, questions could be raised as to how such initiatives may be managed to ensure their effectivity. To address such concerns the South African Department of Constitutional Development commissioned a study on the status of municipal-community partnerships in 1999. The study involved 22 municipalities, 29 civil society organizations and 25 case study surveys. Emanating from the study was a report that reflected some insightful results. The findings generally indicate the limited or ineffective nature of the community consultation or participation approach generally prevalent in South Africa.

Local governments generally confuse municipal community partnerships with community participation and employment programmes (Cranko \& Khan, 1999: 2). The true spirit of partnership and the intensive involvement of the community in the activities of the local government are not yet well cemented. The research has indicated that municipalities' primary motivation for the establishment of municipal community partnerships is to supplement capacity or 
enhance the cost-effectiveness of services. Some interest exists among municipalities to establish municipal community partnerships to enhance job creation and economic empowerment. Community contact and improved services, as such, were not indicated as being the primary reasons why municipalities enter into municipal-community services (Cranko \& Khan, 1999: 3). Municipalities experience a number of constraints regarding the establishment of effective municipal community partnerships and cite inter alia the following:

- The political divisions and conflicts within communities.

- A lack in capacity to manage the processes of planning implementation and monitoring of development outputs.

- Local government capacity to engage in true partnerships is ascribed to limited skills, expertise and commitment among its officials.

- Local government experiences a general of lack of adequate administrative and financial resources to support municipal-community partnerships.

- Differences between the organizational and operational ethos of partners are sometimes difficult to reconcile. This state of affairs causes of many misunderstandings, divisions and mistrust in interactions and exchanges between local governments and their stakeholders.

- The ad hoc nature of community partnerships tends to "projectise" development, which results in a breakdown of the engagement once the projects are finalized.

Non-governmental Organizations are primarily motivated by the benefits of pooling resources and the need for increased financial sustainability. An important aspect that motivates non-governmental organizations is the potential that community partnerships carry in empowering communities (Cranko \& Khan, 1999: 3). Non-governmental organizations identify the following barriers in the establishment of community partnerships:

- Local government in many areas lack the appropriate technical and managerial capacity to deal with municipal-community partnerships and do not have the ability to identify, design and manage and monitor the outputs of partnerships.

- Non-governmental organizations and municipalities differ in their organizational ethos. Municipalities are perceived as being overly bureaucratic, their responsiveness to community proposals is lengthy and many staff members are not committed to engaging with service providers on alternative delivery strategies in a sustained way.

- Politicians and municipal officials are not sensitive to the complex social and economic processes prevailing within communities. 
- Officials often neglect to fully engage with communities and community representatives and thereby forfeiting the opportunity to build true partnerships.

- Municipal departments operate in a non-integrated manner that results in unsustainable development.

It is evident from the above findings that the situation in South African local government generally does not reflect the municipal-community partnership ideal that it should provide mechanisms for more effective communication and the resolution of development deadlocks. Co-operation should be improved and a new understanding about roles, responsibilities, duties and obligations in service provision should be created. Current thought on the true nature of partnerships is that it should be underpinned by policies of decentralization. This recognizes the role of lower levels (spheres) of government to steer developmental initiatives and to ensure effective and efficient service provision (Cranko \& Khan, 1999: 20).

In addition to the legislation quoted (supra) concerning the South African government's policy on community participation, the following table indicates a comprehensive policy framework for engagement in partnerships. The policy framework originates from the recognition of the South African Government that it faces constraints in terms of human, financial and technical capacity to deliver sustainable development and that a comprehensive set of policies are needed to guide the process. The policies cited are currently in various stages of development or implementation.

\section{South African policy framework for engagement in partnerships}

\section{- Macro-economic reform \\ The Growth, Employment and Redistribution strategy (GEAR) makes provision for a social compact (wage, price and productivity agreement) and emphasizes partnerships as a vehicle for service delivery and economic growth. Both of these impact on the way local government organizes its activities and discharges its duties. \\ - $\quad$ Reconstruction and development \\ The Reconstruction and Development Programme (RDP) places the empowerment of institutions of civil society as a fundamental aim of government's development approach. Structured consultation processes at all levels of government will be introduced to ensure participation in policymaking, planning and project implementation. In this way, government will draw on the creative energy of communities.}




\section{- $\quad$ Competition policy}

A competition policy makes provision for the removal of barriers to entry in an accountable and transparent way through a public forum and an independent tribunal. The decisions of the Competition Board impacts on local government's Local Economic Development programmes and the type of support provided by community service organizations.

\section{- Community based public works programme}

The Community Based Public Works Programme regards non-governmental organizations and local governments as implementing agencies being responsible for project management. In this regard, municipal-community partnerships are important in public works programmes.

\section{- A national infrastructure plan}

The Consolidated Municipal Infrastructure Programme provides grants to local authorities for the provision of infrastructure to poor households. Each municipality should, in consultation with the beneficiaries (stakeholders), determine the package and level of services required. It is envisaged that through the Consolidated Municipal Infrastructure Programme partnerships between municipalities and civil society will become more structured and dynamic.

\section{- $\quad$ Restructuring of state assets}

Participation by organized labour and employees of relevant enterprises in restructuring public enterprises and service delivery is guided by the principles of inter alia Batho Pele. These partnerships range from building institutions, removing boundaries and shifting the balance between state and the market (from internal reform to privatization).

\section{- $\quad$ Non-profit Organizations Act}

The Non-profit Organizations Act, which establishes the National Development Agency, promotes a co-operative relationship between civil society and government. The objectives of the National Development Agency is to contribute towards poverty eradication, to assist in capacity building to improve service delivery and to promote dialogue between relevant government spheres and stakeholders.

\section{- Municipal service partnerships policy}

The Municipal Services Partnership policy framework envisages partnerships and the type of contractual arrangements that are informed by the aims and objectives of integrated development plans made compulsory in local government by legislation (Municipal Systems Act, 2000). This ensures that developmental objectives are duly negotiated between the relevant stakeholders.

Cranko and Khan, 1999: 23-26 


\section{Business-municipal-community partnerships}

The global trend of reduced spending by governments has resulted in businesses to become increasingly involved in playing active roles in development. In this regard the current trend is to engage in public-private partnerships (PPPs) in an attempt to improve service delivery to specific communities. In the local government sphere, various public-private partnerships are initiated to address service delivery gaps in for instance the sectors of water, transport, waste management, parks and recreation and emergency services. Public-private partnerships comprise not only business (in its various forms e.g. multinational companies and small, medium and micro enterprises) but also non-governmental organizations and community based organizations (Van Niekerk, Van der Walt \& Jonker, 2001: 256). According to Van Niekerk et al. (2001: 256) PPPs can assist in empowering local communities and encourage local economic development. Furthermore, a partnership can be viewed as a continuous relationship and a definite process. Such partnerships involve active interactivity and are based on the following principles: Particular skills; cost effectiveness and service efficiency; effective public participation; continued government responsibility; a proper contractual relationship, monitoring process and regulatory framework; and a good working relationship between the government authority and the service delivery agent. In view of the aforementioned, it is important to note Badshah's comments in the City Development Strategies-publication (1999: 27) that a tension exists between governments, businesses and civil society concerning their respective roles in the community. The tension is unlikely to abate and unless interaction and partnership among the different above-mentioned sectors are established (City Development Strategies, 1999: 27).

According to City Development Strategies (1999: 28) a number of lessons could be learned from international "best practice" cases with regards to partnerships between business, local government and the community:

First, for partnerships between business, the community and local government to be effective, the way in which cities are managed should be altered. What is needed is increased transparency and accountability. Decision-making processes should allow stakeholders a direct say in what a particular outcome may bring. All government institutions should be redirected towards institutionalizing partnership engagements. Short-term commitment towards engaging in partnerships with business stakeholders will not prevail because of the tendency of the political landscape to change frequently. The culture of management in government should therefore change comprehensively in order to create a continuum of stakeholder negotiations in this regard. 
Second, partnerships fail because of a lack of trust between the stakeholders. A result of this may be that there is a lack of commitment on behalf of all parties to see the process through and achieve the desired results.

Third, there is an element of capacity building and education involved from business' side in that it should assist non-governmental organizations and community organizations to develop as entities so that they, in turn, can become the cohesive factor in these partnership arrangements. This calls for a true commitment from within local government, business and the community, which cannot be enforced from any outside agency.

Fourth, local governments should open up the process of decision-making to include participation of all the stakeholders (City Development Strategies, 1999: 28).

In brief, the above lessons teach that a new approach towards managing cities should be adopted wherein constant negotiation takes place between the stakeholders, where all concerned parties are involved in decision-making. In addition, improved consultation and decision-making will be achieved if community organizations are capacitated to play their roles effectively with the assistance of business and local government.

\section{CONCLUSION}

In the preceding discussion it became apparent that South African local governments should re-assess their roles in their areas of municipal jurisdiction. Management in local government should adapt to new approaches concerning how to best improve municipal service rendering and how to achieve developmental objectives on the basis of sustainability. Community participation and stakeholder negotiations challenge traditional views on decision-making and responsibility in the municipal environment. Resourceconstrained public institutions working in close collaboration community stakeholders and the private sector will present municipalities with challenges that are different from traditional local government affairs. Democratic, transparent and accountable practices are highly regarded traits where local governments strive towards legitimacy in view of their communities and where investment in development projects is sought. An effective way of meeting local government objectives could therefore be to establish and institutionalize community participation and most importantly, stakeholder negotiation to the extent that it will be viewed not as an ad hoc event but rather a continuous process. Out of necessity, the divergent views and needs would require frequent negotiation and supportive resources should be made available to prove local 
government's commitment towards engaging in partnerships with stakeholders. The ideal is to form true partnerships with municipal stakeholders through a process of consistent involvement in decision-making.

This could support the entrenchment of a culture of stakeholder negotiations in all matters that impact on the parties concerned. Finally, the trust-building dynamics among different stakeholders and within different municipalities motivate the need for other spheres of government to abstain from overregulating community participation and stakeholder negotiation processes other than by creating a broad policy environment to allow the stakeholders to facilitate this process themselves. Municipalities should in this regard rather be supported through offering appropriate mechanisms, resources and advice.

Much applied research is still needed in this area. The South African local government system is still evolving and it is dependent on the processes of community participation and stakeholder negotiation to ensure its ultimate effectiveness.

\section{REFERENCES}

1 BECKENSTEIN, A.R. LONG, F.J. ARNOLD, M.B. \& GLADWIN, T.N. (1996) Stakeholder Negotiations. Exercises in Sustainable Development, Chicago: Irwin.

2 CITY DEVELOPMENT STRATEGIES (1999) "Business Citizenship: New Approaches to Social Investment in Cities", City Development Strategies Initiative, Issue no 1 (October).

3 COETZEE, J.K. GRAAFF, J. HENDRICKS, F. \& WOOD, G. (eds.) (2001) Development. Theory, Policy, and Practice, Cape Town: Oxford University Press Southern Africa.

4 CRANKO, P. \& KHAN, F. (1999) Municipal Community Partnerships, Department of Constitutional Development.

5 DU TOIT, D., KNIPE, A., VAN NIEKERK, D., VAN DER WALT, G. \& DOYLE M. (2001) Service Excellence in Governance, Sandown: Heinemann Publishers (Pty) Ltd.

6 DEPARTMENT OF PROVINCIAL AND LOCAL GOVERNMENT (2000) Research compiled by: Oranje, M. Harrison, P. Meyer, E. Van Huyssteen, E. October, A Policy Paper on Integrated Development Planning.

7 DEPARTMENT OF PROVINCIAL AND LOCAL GOVERNMENT IDP Guide Pack, Guide 1.

8 FOX, W. \& MEYER, I.H. (1995) Public Administration Dictionary, Kenwyn: Juta \& Co Ltd. 
9 MERSHAM, G.M., RENSBURG, R.S. \& SKINNER, J.C. (1995) Public Relations, Development and Social Investment: A Southern African perspective, Pretoria: J.L. van Schaik.

10 REDDY, P.S. (1996) (ed.) Perspectives on Local Government Management and Development in Africa, Durban, South Africa: Department of Public Administration, University of Durban-Westville.

11 SPOELSTRA, M. \& PIENAAR, W. (1996) Negotiation. Theories, Strategies \& Skills, Kenwyn: Juta \& Co. Ltd.

12 SOUTH AFRICA, REPUBLIC (1996) The Constitution of the Republic of South Africa, Act 108 of 1996. Pretoria: Government Printer.

13 SOUTH AFRICA, REPUBLIC (2000) Municipal Systems Act, Act 32 of 2000, Pretoria: Government Printer.

14 SOUTH AFRICA, REPUBLIC (1997) White Paper on Transforming Public Service Delivery, Pretoria: Government Printer.

15 SOUTH AFRICA, REPUBLIC (1998) White Paper on Local Government. Pretoria: Government Printer.

16 SWANEPOEL, H. \& DE BEER, F. (1996) Communication for Development. A Guide for Fieldworkers, Johannesburg: International Thompson Publishing (Southern Africa) (Pty) Ltd.

17 VAN DER WALT, G. \& KNIPE, A. (1998) Project Management for Strategic Change and Upliftment, Johannesburg: International Thompson Publishing (Southern Africa) (Pty) Ltd.

18 VAN NIEKERK, D., VAN DER WALT, G. \& JONKER, A. (2001) Governance, Politics, and Policy in South Africa, Goodwood, Cape Town: Oxford Southern Africa. 